УДК 33 JEL H29

Шевырков Леонид Владимирович

специалист 1 класса аналитического отдела, Межрайонная инспекция Федеральной налоговой службы № 3 по Московской области, г. Москва e-mail: spidermail@inbox.ru

\section{Shevyrkov Leonid}

Senior specialist of the 1st class of the analytical department, Inter-district Tax Inspectorate №o 3 for the Moscow region, Moscow e-mail: spidermail@inbox.ru

\section{МЕТОДИКА ОЦЕНКИ НАЛОГОВЫХ ЛЬГОТ НА МЕСТНОМ УРОВНЕ}

\begin{abstract}
Аннотация. Проанализированы методики оценки эффективности налоговых льгот, действующие на местном уровне. Ретроспективный анализ позволил автору выявить преимущества и недостатки предлагаемых методик и сформировать авторское видение по вопросу челесообразности оченки налоговых льгот и преференций по местным налогам и торговому сбору. Предлагаемая методика позволит наиболее качественно оченить налоговые преимущества на уровне местных органов самоуправления с использованием сводной эффективности. В работе применяется формально-логический метод, системный метод, метод математического моделирования.

Ключевые слова: сводная эффективность, бюджетная эффективность, экономическая эффективность, сочииальная эффективность, сумма выпадающих доходов.
\end{abstract}

\section{METHODOLOGY FOR ASSESSING TAX BENEFITS AT THE LOCAL LEVEL}

\begin{abstract}
The methods of assessment of efficiency of tax benefits operating at the local level are analyzed. Retrospective analysis allowed the author to identify the advantages and disadvantages of the proposed methods and to form the author's vision on the feasibility of assessing tax benefits and preferences for local taxes and trade duties. The proposed method, the top quality will allow to estimate tax benefits to local authorities from the use of aggregate efficiency. The paper applies the formal-logical method, the system method, the method of mathematical modeling.

Keywords: combined efficiency, budget efficiency, economic efficiency, social efficiency, amount of falling income.
\end{abstract}

На современном этапе идет активное обсуждение предлагаемых методик оценки эффективности налоговых льгот, но единого мнения по этому вопросу нет. По мнению ведущих экономистов области налогообложения, налоговые льготы - форма реализации, регулирующей (стимулирующей) функции налогов [3]. Накопленный опыт показывает, что формирование системы налогового стимулирования, включающего варьирование объема налоговых поступлений, применение гибкого подхода к ставкам налогов, является одним из основных способов государственного налогового регулирования.

Методики оценки эффективности налоговых льгот в большинстве регионов часто повторяются по некоторым показателям и практически не позволяют определить зависимость между налоговыми льготами и поступлениями, т. е. невозможно выявить, за счет влияния какого фактора (льготы, изменения законодательства, улучшения конъюнктуры рынка) изменились налоговые поступления [2].

Объекты оценки - экономическая, бюджетная и социальная эффективность налоговых льгот по местным налогам. Оценку выполняют уполномоченные органы для отдельно взятых местных налогов по отношению к каждой из предоставленных льгот и к каждой категории их получателей, для случаев отдельных видов деятельности. Уполномоченный орган - орган администрации района, определяющийся постановлением главы администрации района.

Источник сведений для расчета оценки эффективности налоговых льгот - данные налоговой отчетности. При отсутствии необходимых сведений в этих видах отчетности. или при невозможности ими воспользоваться применяется статистическая отчетность, предоставленная органами статистики и прочие виды информации, такие как оценки экспертов и данные, предоставляемые получателями налоговых льгот или лицами, претендующими на их получение по запросу соответствующего органа.

Уполномоченный орган при проведении оценки эффективности налоговых льгот, использует следующие показатели:

(С) Шевырков Л.В., 2018 
- ставка налога;

- налогооблагаемая база по налогу на начало и конец отчетного периода;

- льготная ставка налога;

- сведения об отказах налогоплательщиков пользоваться предоставленной льготой;

- сумма сокращения базы налога за истекший период отчетного года;

- использование средств, высвободившихся в результате предоставления льгот или полученных

плательщиками налогов в счет льгот, строго по целевому назначению;

- стоимость основных фондов на начало и конец отчетного периода;

- фонд оплаты труда на начало и конец отчетного периода;

- сумма задолженности по уплате налогов в бюджет района;

- сумма начисленных налогов в бюджет района;

- сумма уплаченных налогов в бюджет района.

Проведенный анализ налоговых льгот показывает, что в основном льготы носят социальный характер и направлены на:

- поддержку организаций, осуществляющих социальную защиту граждан;

- снижение налоговой нагрузки бюджетных организаций;

- социальную поддержку населения.

Система налоговых льгот, выступая в роли действенного экономического регулятора, должна отвечать определенным требованиям, при невыполнении которых ее функционирование становится нецелесообразным [6].

Предложенный в 2014 г. Министерством экономического развития Российской Федерации (далее - РФ) совместно с Министерством финансов РФ проект единой комплексной оценки эффективности всех видов налоговых льгот и иных инструментов налогового стимулирования, предусмотренных Налоговым кодексом РФ (далее НК РФ), содержит следующие показатели оценки эффективности налоговых льгот [5]:

1. Бюджетная эффективность налоговой льготы. Этот показатель характеризует влияние предоставления налоговой льготы на объемы доходов местных бюджетов.

Коэффициент бюджетной эффективности КБЭ налоговых льгот рассчитывают по следующей формуле:

$$
\text { КБЭ=БЭ-ВД, }
$$

где БЭ - сумма бюджетной эффективности налоговых льгот; ВД - сумма выпадающих доходов бюджета от предоставления налоговых льгот.

Налоговые льготы имеют высокую бюджетную эффективность, если коэффициент эффективности налоговых льгот больше либо равен единице. Налоговые льготы имеют низкую бюджетную эффективность, если коэффициент эффективности налоговых льгот меньше единицы.

Сумму выпадающих доходов бюджета ВД в связи с предоставлением налоговых льгот рассчитывают по следующим формулам:

$$
\text { ВД }=\text { СНБ } \cdot \text { НС, }
$$

если предоставление льготы сводится к освобождению от налогообложения части базы налога. Здесь СНБ размер сокращения базы налога по причине предоставления льгот; НС - действующая в период предоставления льгот ставка налога;

$$
\text { ВД =БНЛ } \cdot(\text { НСБ }- \text { НСЛ }) \text {, }
$$

если предоставление льготы сводится к обложению части базы налога по пониженной налоговой ставке. Здесь БНЛ - размер базы налога, на которую распространяется действие льготной ставки; НСБ - действующая (предполагаемая) в период предоставления льгот базовая ставка налога; НСЛ - льготная ставка налога.

Оценку бюджетной эффективности налоговых льгот проводят за период не менее трех лет. Низкие результаты от предоставления льготы в сравнении с фактическими потерями бюджета, свидетельствует о низкой эффективности налоговых льгот. При выявлении подобных результатов налоговые льготы не должны 
предоставляться, а уже предоставленные льготы должны быть отменены. Исключения могут быть сделаны в отношении отдельных видов деятельности, определенных прогнозом социально-экономического развития поселения в качестве приоритетных.

2. Экономическая эффективность налоговой льготы - наметившаяся за 5 лет действия льготы положительная динамика в запланированных ключевых показателях, для стимулирования которых была введена (вводится) налоговая льгота. Это может быть опережающая динамика инвестиций в основной капитал у налогоплательщиков, расширение и обновление производства, проведение научно-исследовательских и опытно-конструкторских работ (далее - НИОКР), создания новых рабочих мест и т. д.

В качестве коэффициентов экономической эффективности могут использоваться показатели инновационной деятельности предприятий: коэффициент налоговой экономии расходов на НИОКР, коэффициент эффективности налогового льготирования инновационной деятельности, налогоемкость прибыли от инновационной деятельности, коэффициент налоговой нагрузки инновационной деятельности и так далее. Кроме того, все эти показатели можно разделить на 2 группы: коэффициенты эффективности первого порядка, оказывающие прямое влияние на инновационную деятельность, и коэффициенты второго порядка, влияющие опосредованно [4].

3. Социальная эффективность налоговой льготы определяется показателями, подтверждающими повышение социальной защищенности населения, создание благоприятных условий развития социальной инфраструктуры. Данный показатель исчисляется при предоставлении налоговой льготы отдельным категориям населения, некоммерческим организациям.

В качестве социальной эффективности рассматривают повышение заработной платы, создание новых рабочих мест, совершенствование условий и охраны труда, трудоустройство социально незащищенных лиц и создание для них благоприятных условий жизнедеятельности, совершенствование качества услуг, предоставляемых налогоплательщиком.

На сегодняшний день во всех субъектах и муниципалитетах России разработаны и приняты в отношении всех льгот региональные методики оценки эффективности. Но практически их применяют не в полном объеме. Некоторые регионы выполняют оценку льгот лишь для отдельных категорий. Например, в Московской области оценку проводят сугубо в отношении действующих льгот, в то время как в Ленинградской области и Якутии только в отношении планируемых к предоставлению [5].

В ряде муниципальных образованиях по местным налогам и сборам проводится расчет эффективности применения налоговых льгот. К таким муниципальным образованиям относят города Барнаул, Хабаровск, Киров, Пензу, Пермь, Ульяновск, Ярославль. В иных муниципальных образованиях оценку эффективности проводят перед принятием нормативных актов о предоставлении льгот, либо оценка ограничивается только бюджетной эффективностью налоговых льгот. В других действует методика оценки бюджетной и социальной эффективности налоговых льгот, предоставляемых муниципальным унитарным предприятиям (г. Пенза).

Изложенное выше позволяет сделать вывод, что оценка эффективности налоговых льгот в различных регионах России носит фрагментарный, бессистемный и эпизодический характер, отсутствуют единые формы отчетности результатов оценки, что усложняет получение объективной информации для принятия экономически обоснованных решений по применению действительно эффективных льгот, а также их отмене в случае неэффективности.

Налоговые льготы вводят не только для регулирования экономики, но и для облегчения налогового бремени отдельным налогоплательщикам. Однако оценка социальной эффективности носит приблизительный характер. Данные, полученные при такой оценке, не могут быть оценены с математической точки зрения, т. е. результаты оценки социальной и бюджетной эффективности различны.

Бюджетная эффективность является самым верным индикатором эффективности той или иной налоговой льготы. Бюджетная эффективность репрезентативна и выражается в числовых значениях. Бюджетную эффективность легче систематизировать и рассчитывать на основании одной схемы по всей стране. Данная схема может иметь погрешности в виде региональных и местных особенностей.

Экономическая эффективность, как и бюджетная, представлена численными значениями. Однако у разных экономических субъектов за один и тот же период может быть разная экономическая эффективность. В данном случае следует группировать экономические субъекты по объему оборота, сфере деятельности и т. д. Несмотря 
на это, экономические показатели у одинаковых по размеру и работающих в одной сфере организаций могут быть разными. Произойти это может в силу многих причин, например, плохого менеджмента. В связи с этим в расчет нужно брать в первую очередь крупные (градообразующие) предприятия, создающие большое количество рабочих мест.

Сказанное выше не значит, что в расчет нужно брать только бюджетную эффективность. Должны использоваться оценки всех видов, но в первую очередь следует унифицировать процесс оценки бюджетной эффективности и систематизировать ее результаты. Социальную и экономическую эффективность должны оценивать муниципалитеты и регионы. Данные методики могут совместно разрабатывать муниципалитеты и федеральные власти и иметь вспомогательный характер при оценке бюджетной эффективности. Социальную эффективность в силу ее специфичности можно оценивать посредствам проведения социологической работы.

Итоговые результаты, полученные при оценке социальной и экономической эффективность, можно в дальнейшем перевести в числа, подходящие для сопоставления с данными, полученными при оценке бюджетной эффективности.

Изучив существующие методики, автор предлагает использовать при оценке налоговых льгот показатель СЭ сводной экономической эффективности, который вычисляется по следующей формуле:

$$
\text { СЭ= (КБЭ }+\mathrm{X} \cdot(\text { КСЭ }+ \text { КЭЭ })-\mathrm{P} / 100,
$$

где X - коэффициент влияния социальной и экономической эффективности; КСЭ - коэффициент социальной эффективности; КЭЭ - коэффициент экономической эффективности; Р - расходы на оценку.

Рассмотрим подробнее расчет коэффициентов Х, КСЭ, КЭЭ из формулы (4). Коэффициент влияния социальной и экономической эффективности Х вычисляют по как отношение

$$
\mathrm{X}=\mathrm{KK} / \mathrm{K} \Pi \text {, }
$$

где КК - качественный коэффициент - табличная единица, разработанная муниципалитетом и федеральными органами власти и исчисляемая в балах (от 1 до 5); КП - количество показателей, используемых тем или иным муниципалитетом.

Коэффициент социальной эффективности КСЭ представляет собой сумму трех величин: адресности предоставления, прозрачности предоставления и широты охвата (примерный перечень). Значение каждого показателя равно определенному количеству баллов:

- адресность предоставления (от 1 до 5 баллов). Адресность принимает значение, равное 1 , если льготополучателей нельзя классифицировать ни по одному основанию, и равна 5 , если льготополучателей можно разделить больше, чем на 4 группы;

- прозрачность предоставления (выявляется с помощью социологического опроса, рассчитывается от 1 до 5);

- широта охвата (повышающий показатель).

Коэффициент экономической эффективности КЭЭ определяется как сумма трех показателей: уровня капитализации, уровня инвестиций и полученной прибыли за условный период (примерный перечень). Уровень капитализации равен отношению двух величин: долгосрочных обязательств к сумме долгосрочных обязательств и собственного капитала организации. Уровень инвестиций представляет собой разность двух величин: инвестируемой суммы, внесенной мелкими и крупными инвесторами за условный период, и инвестируемой суммы, внесенной крупнейшим инвестором за условный период.

Коэффициенты социальной и экономической эффективности (КСЭ, КЭЭ) должны состоять не менее, чем из 3-х показателей. Чем больше число показателей, тем большей точностью обладает формула.

Общий перечень показателей должен быть принят на федеральном уровне. Каждый показатель исчисляется определенным количеством баллов. Качественный показатель зависит от влияния на формулу других показателей (например, показатели социальной эффективности имеют меньшее значение, чем показатели экономической эффективности, а адресность предоставления имеет больший вес, чем прозрачность предоставления) и от экономического субъекта, чья хозяйственная деятельность стала основой для расчета коэффициента экономической эффективности. 
Оценка эффективности предоставленных налоговых льгот должны проводить финансовое управление муниципалитета или управление экономического развития муниципалитета, совместно с Управлением Федеральной налоговой службы по субъекту РФ, аккумулирующим информацию о налоговых поступлениях каждого муниципалитета. Выполнять оценку эффективности применения налоговых льгот целесообразно по каждому налогу по категориям налогоплательщиков. Анализу подлежат льготы в виде уменьшения налогооблагаемой базы и снижения налоговой ставки.

После проведения оценки эффективности предоставленных налоговых льгот уполномоченный орган муниципалитета готовит заключение, на основании которого принимается одно из следующих решений:

- о сохранении предоставленных (планируемых к представлению) налоговых льгот;

- об отмене предоставленных (планируемых к представлению) налоговых льгот;

- о корректировке предоставленных (планируемых к представлению) налоговых льгот.

В части эффективности применения налоговых льгот важным является тот факт, что на налогоплательщиков не возложена обязанность по использованию оставшихся в их распоряжении в результате применения льгот денежных средств на осуществление инвестиционной политики или иных целей, которые подразумеваются при предоставлении налоговых льгот. Получив льготу, налогоплательщик не обременяется обязанностью по ее использованию. В НК РФ отсутствует процедура налогового контроля и налогового мониторинга эффективности налоговых льгот. В этом случае следует обратиться к определению налоговой преференции, данному А. С. Баландиной, в котором указывается основное отличие преференций от льгот: «Налоговая преференция является предоставлением государственных преимуществ в отношении отдельных категорий налогоплательщиков в виде уменьшения сумм налоговых обязательств, носящих императивный характер, на условиях встречных обязательств со стороны плательщика» [1].

Здесь возникает вопрос, являются ли льготы правом или правом и обязанностью одновременно. В НК РФ по-прежнему отсутствует четко прописанная процедуры налогового контроля и налогового мониторинга эффективности налоговых льгот, что делает неосуществимым сбор и подготовку информации в отношении принятия и анализа решений по дальнейшему их применению. Методика единой комплексной оценки эффективности налоговых льгот не получила практической реализации в 2015 г., но работу в данном направлении необходимо продолжить.

Льготы, предоставляемые не физическим лицам, а экономическим субъектам, должны носить обязывающий характер. Возможно, эта обязанность должна быть установлена законодательно и акцептовываться льготополучателем.

Известно, что чаще всего льготы имеют затяжной во времени эффект, приводят к постепенному росту активов налогоплательщика и, таким образом, к будущему увеличению поступлений налогов в бюджетную систему. В связи с чем необходимо ввести в механизм оценки эффективности такое понятие, как совокупный накопленный эффект налоговых льгот, заложив в основу критериальные показатели соотнесения выпадающих доходов бюджета в увязке с финансово-экономической деятельностью субъектов хозяйствования. Однозначно работу по совершенствованию механизма оценки эффективности инструментов налогового стимулирования нужно продолжить в отношении устранения обнаруженных недостатков, повышения объективности и упрощения оценки с целью дальнейшего планирования поступлений налогов в местные бюджеты.

\section{Библиографический список}

1. Баландина, А. С. Анализ теоретических аспектов налоговых льгот и налоговых преференций // Вестник Томского государственного университета. - 2011. - № 4 (16). - 108 с.

2. Кружкова, И. И. Учет и восстановление амортизационной премии // Налоговая политика и практика. - 2010. - № 3. C. $40-45$.

3. Малинина, Т. А. Оценка налоговых льгот и освобождений: зарубежный опыт и российская практика. - М.: Ин-т Гайдара, 2010. - 212 c.

4. Фишер, О. В. и др. Оценка эффективности налогового стимулирования инновационной деятельности в России / О. В. Фишер, Л. В. Перекрестова, Т. П. Ломакина, М. Ш. Иризепова // «Налоги и налогообложение». - 2014.- № 2. C. 156-173. 
5. Савина, О. Н. Проблемы проведения оценки эффективности инструментов налогового стимулирования: анализ современной практики / О. Н. Савина, М. А. Жажин // Налоги и налогообложение. - 2015.- № 8 (134). - С. $580-591$.

6. Черник, Д. Г. Пути реформирования налоговой системы // Экономика. Налоги. Право. - 2013. - № 1. - С. 54-64.

\section{References}

1. Baladina A. S. Analiz teoreticheskikh aspektov nalogovykh lgot i nalogovykh preferentsiy [Analysis of theoretical aspects of tax benefits and tax preferences] // Vestnik Tomskogo gosudarstvennogo universiteta, 2011, I. 4 (16), 108 p.

2. Kruzhkova I. I. Uchet i vosstanovleniye amortizatsionnoy premii [Accounting and recovery of amortization premiums] // Nalogovaya politika i praktika, 2010, I. 3, pp. 40-45.

3. Malinina T. A. Ocenka nalogovyh l'got i osvobozhdenij: zarubezhnyj opyt i rossijskaya praktika [Assessment of tax benefits and exemptions: foreign experience and Russian practice]. M.: In-t Gajdara, 2010. 212 p.

4. Fisher O. V. Otsenka effektivnosti nalogovogo stimulirovaniya innovatsionnoy deyatelnosti v Rossii [Evaluation of the effectiveness of tax incentives for innovation in Russia] // O. V. Fisher, L. V. Perekrestova, T. P. Lomakina, M. Sh. Irizepova // «Nalogi i nalogooblozheniye», 2014, I 2, pp. 156-173.

5. Savina O. N., Zhazhin M. A. Problemy provedeniya otsenki effektivnosti instrumentov nalogovogo stimulirovaniya: analiz sovremennoy praktiki. [The problems of assessing the effectiveness of tax incentive tools: analysis of current practice] // Nalogi i nalogooblozheniye, 2015, I. 8 (134), pp. 580-591.

6. Chernik D. G. Puti reformirovaniya nalogovoy sistemy [Ways of Reforming the Tax System] // Ekonomika. Nalogi. Pravo, 2013, I. 1, pp. 54-64. 